DOI: $10.14451 / 1.175 .102$

\title{
ТИПЫ ХОЗЯЙСТВ И КАЧЕСТВО МОЛОКА: ПРОБЛЕМЫ И ИХ РЕШЕНИЯ
}

\author{
(c) 2019 Шеншин Александр Евгеньевич
}

доктор экономических наук, профессор, зав. кафедрой гражданско-правовых дисциплин Институт государственного администрирования, Россия, Москва

E-mail: alshensh@gmail.com

(c) 2019 Майоров Александр Альбертович

доктор технических наук, профессор

Сибирский научно-исследовательский институт сыроделия Федерального Алтайского научного

центра агробиотехнологий, Россия, Барнаул

\section{(c) 2019 Сурай Наталья Михайловна}

кандидат технических наук, доцент кафедры экономики и управления

Московский государственный университет технологий и управления

имени К.Г. Разумовского (ПКУ), Россия, Москва

E-mail: natalya.mixajlovna.1979@mail.ru

\section{(c) 2019 Носов Владимир Владимирович}

доктор экономических наук, профессор кафедры экономики и управления, зам.директора по научной работе Института экономики, менеджмента и права

Московский государственный университет технологий и управления имени К.Г. Разумовского (ПКУ), Россия, Москва

В данной статье проведен анализ производства молока и его качества на предприятиях (хозяйствах) с различной системой организации и различными объемами производимого молока.

Ключевые слова: молоко, сыропригодность молока, сельскохозяйственные организации, личные подсобные хозяйства, фермерские хозяйства, молочная промышленность, молочные предприятия, качество молока, объем производства молока.

В общепринятой статистике Российской Федерации принято разделять производимое молоко на три группы: произведенное сельскохозяйственными организациями, фермерскими хозяйствами и личными хозяйствами. Такое деление является условным по принципу юридической констатации организационной принадлежности к той или иной группе. Иногда на личном подворье имеется больше молочного скота, чем в фермерском хозяйстве. Для потребителей молока, производителей молочной продукции значение имеет не источник поставок молока, его качество. Качество молока и его состав зависит от целого ряда факторов: здоровья животных, их породы, условий содержания и кормления, системы доения, хранения и транспортирования молока.

Всем производителям молока известны требования, предъявляемые к молоку-сырью. Наиболее высокие требования к молоку предъявляет сыродельная промышленность и поэтому возник термин «сыропригодность молока».
Он представляет собой комплекс показателей, включающий требования к санитарным (микробиологическим) характеристикам, физико-химическому составу, механической загрязненности, температуре и др. Большая часть усилий предприятий по выработке молочной продукции в отношении обеспечения или повышения ее качества связана с коррекцией технологических параметров производства, подготовкой молока для технологических процессов. Чаще всего мероприятия по улучшению показателей качества связаны с очисткой от механической загрязненности, спор микроорганизмов, удаления посторонних запахов (дезодорация), дополнительной температурной обработкой, созреванием молока с использованием специальной микрофлоры. Естественно, что технология выработки натурального сыра, как самая требовательная к стабильности показателей в условиях изменения качества молочного сырья, вынуждена использовать почти все методы обеспечения стабильности процессов производства и каче- 
ства готового продукта. Помимо обязательных элементов очистки с применением фильтров и молокоочистителей, на этапе подготовки молока к выработке сыра, применяют бактофугирование, дезодорирование, двойную тепловую обработку, созревание молока с добавлением закваски. Дальнейшая коррекция технологии может быть реализована на последующих этапах производства.

Для производителя сыра идеальным вариантом было бы получение молока, готового к выработке сыра без каких-либо предварительных манипуляций. Но это пока только мечты, а на практике приходится затрачивать время, тратить ресурсы, с тем, чтобы не терять на качестве продукции. В экономике сыродельного производства качество поступающего сырья имеет первостепенное значение. Наибольшее влияние на количество произведенного продукта из единицы сырья имеет массовая доля белка, от его содержания в молоке напрямую зависит выход сыра. В целом же эффективность выработки продукции маслосыроделия зависит от количества жира и белка в поставляемом молоке. Среднестатистическое молоко в России содержит в своем составе 3,8\% жира, 3,1\% белка. Эти показатели являются очень среднестатистическими. В различных хозяйствах различные породы коров могут давать молоко с массовой долей жира до $4,5 \%$, а белка до $3,5 \%$.

В этой связи для оценки потенциальных сырьевых ресурсов и перспектив оценки раци- онального использования сырьевых ресурсов имеет смысл проанализировать ситуацию в части производства молока и его показателей.

В России молока производится ежегодно находится на уровне 31 млн. тонн в год. В этом объеме примерно в равных долях участвуют сельскохозяйственные организации (далее $\mathrm{c} / \mathrm{x}$ ) и личные подсобные хозяйства (далее ЛПХ), хозяйства населения. Так в 2017 г. с/х организациях было произведено 15639 тыс.тонн молока, в хозяйствах населения 13112 тыс. т. В крестьянских (фермерских) хозяйствах и у индивидуальных предпринимателей (далее КФХ и ИП) в этот же период этот объем составил 2368 тыс. т., или 7,6\% от общего объема. Из общего объема было продано и поступило в переработку 21200 тыс. т молока. Это соотношение характеризует показатель «товарность молока». В 2017 году он составил более $68 \%$, что на $1,93 \%$ больше, чем в предыдущем году [1]. Показатель товарности для различных типов хозяйств различен. Так, наибольший показатель имеют с/х организации, он составляет в общем объеме товарного молока $70 \%$, для хозяйств населения эта доля $-22 \%$, крестьянские фермерские хозяйства и индивидуальные предприниматели - 8\%.

В целом для всех типов хозяйств характерна сезонность производства. На рисунке 1 приведен график поквартального производства молока тремя основными типами хозяйств.

Следует сказать, что положительной является динамика изменения показателей у кре-

\section{Производство молока в различных категориях} хозяйств поквартально

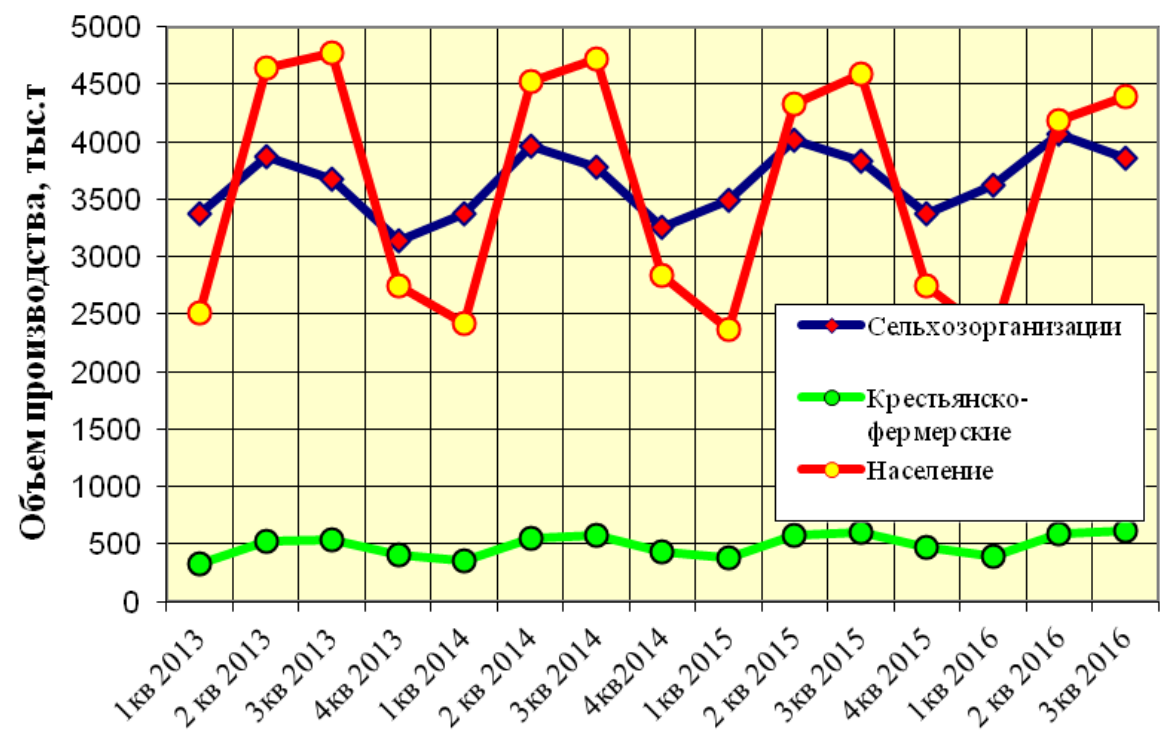

Puc. 1. Производство молока в России 
стьянских фермерских хозяйств и индивидуальных предпринимателей. Так, за период с 2013 по 2018 г. у этой категории поголовье коров выросло с 1040 тыс. голов до 1231,6 тыс. голов в то время, когда общая численность молочного стада России сократилось с 8660,5 тыс. голов до 8202,6 тыс. голов. Сокращение численности произошло в ЛПХ на $10,7 \%$, а в с/х организациях на $6 \%$. Некоторое увеличение объемов производства молока произошло за счет повышения продуктивности скота. Так, в с/х организациях за этот период продуктивность возросла с 4519 кг до 5838 кг молока в год от одного животного.

Большое влияние на производство молочной продукции оказывает сезонность. Значительная часть молока производится в летний период года. В июне месяце на производство поставляется максимальное количество, в ноябре месяце - минимальное. Соотношение объемов поставок молока в ноябре к объемам в июне определяют как «показатель сезонности». По данным Росстат «Союзмолоко» совместно с АЦ «MilkNews» коэффициент сезонности в России в 2016 г составил 0,637 [2]. Такие колебания в поставках молока оказывают негативное влияние на работу предприятий по выпуску молочной продукции. Коэффициент сезонности для различных регионов России колеблется от 0,947 до 0,362. Также он подвержен изменениям для различных типов хозяйств в зависимости от породности, условий содержания скота, кормления и других факторов. Сезонность сказывается и на составе и качестве молока.

Был проведен анализ поступления молока на Белебеевский молочный комбинат (г. Белебей, Башкортостан) от различных поставщиков.

На графиках (рис. 2 и 3) приведены усредненные данные по содержанию жира и белка в молоке, поступающем на переработку.

Анализ проводился в каждой партии, поступающего на комбинат молока, в течение года. Хозяйства были условно разделены на 6 групп по суточному объему поставок молока. В первой строке представлены частные хозяйства. В следующих строках: первая, вторая, третья, четвертая и пятая группы представляют хозяйства, поставляющие соответственно: первая -до 300кг, 2 группа -(300-1000) кг молока в сутки, 3 группа -(1000-2000) кг/сутки, 4 группа -(2000-5000) кг/ сутки и 5 группа -(5000-10000) кг/сутки.

Минимальная величина массовой доли жира в поступающем молоке характерна для летнего периода, и она достаточно стабильна для хозяйств различного уровня. Увеличение массовой доли жира наблюдается в осенний период. В этот же период происходит и увеличение массовой доли белка в молоке. Характерным является то, что массовая доля белка в период март, апрель, май в молоке, предназначенном для производства сыра, находится на низком уровне, что снижает выход сыра. Достаточный уровень белка обеспечивают крупные хозяйства, для которых минимальный уровень белка в поставляемом молоке не снижается в течение года ниже 3,2\%. (рис.4).

Из таблицы 1 видно, что сумма основных показателей (жир + белок), определяющих выход продукции, наибольшей является у пятой груп-

Доля молока, поступающего на Белебеевский МК по месяцам

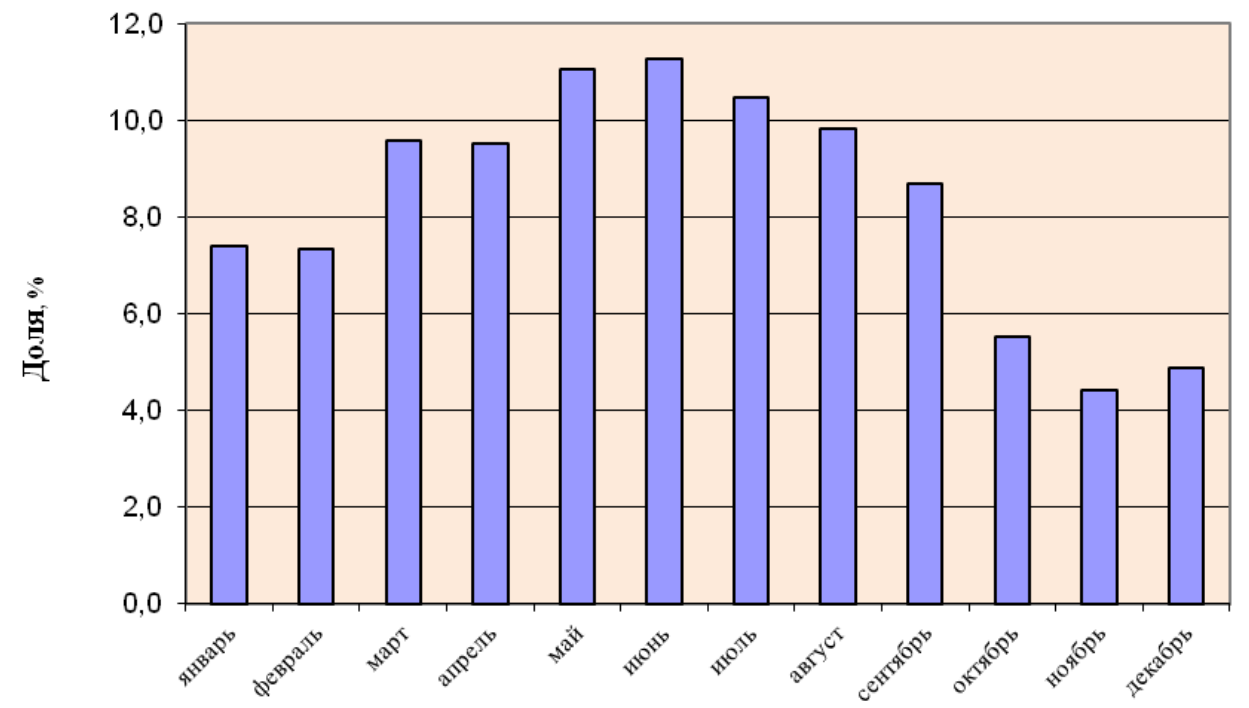

Pис. 2. Объемы молока, поступающего на Белебеевский молочный комбинат, рассчитанный в долевом отношении (в процентах) 
Таблица 1. Показатели состава молока, поступающего на Белебеевский МСК от различных групп поставщиков

\begin{tabular}{|c|c|c|c|c|}
\hline Группа поставщиков & $\begin{array}{c}\text { Доля в объеме } \\
\text { поставок молока, \% }\end{array}$ & $\begin{array}{c}\text { Среднее значение } \\
\text { МД белка, \% }\end{array}$ & $\begin{array}{c}\text { Среднее значение } \\
\text { МД жира, \% }\end{array}$ & $\begin{array}{c}\text { Среднее значение } \\
\text { МД жира } \\
\text { +Мд белка, \% }\end{array}$ \\
\hline Частный сектор & 7,88 & 3,0 & 3,68 & 6,68 \\
\hline 1 группа & 5,49 & 3,22 & 3,82 & 7,04 \\
\hline 2 группа & 5,83 & 3,20 & 3,79 & 6,99 \\
\hline 3 группа & 5,40 & 3,20 & 3,82 & 7,02 \\
\hline 4 группа & 12,13 & 3,22 & 3,85 & 7,07 \\
\hline 5 группа & 63,29 & 3,31 & 3,85 & 7,16 \\
\hline
\end{tabular}

Массовая доля белка в молоке, поступающем на переработку, \%

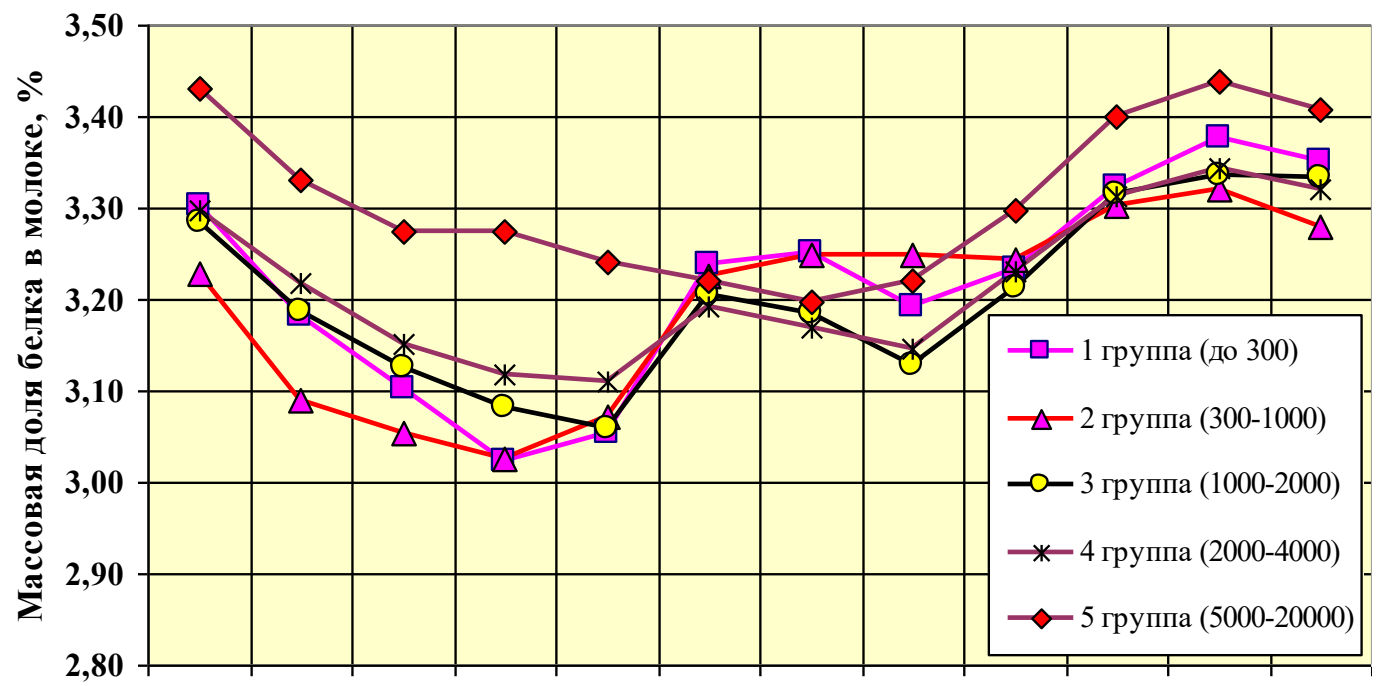

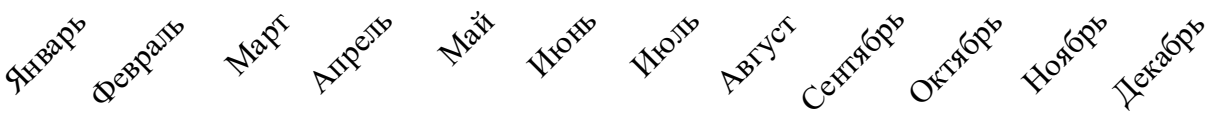

Рис. 3. Массовая доля белка в молоке от различных хозяйств

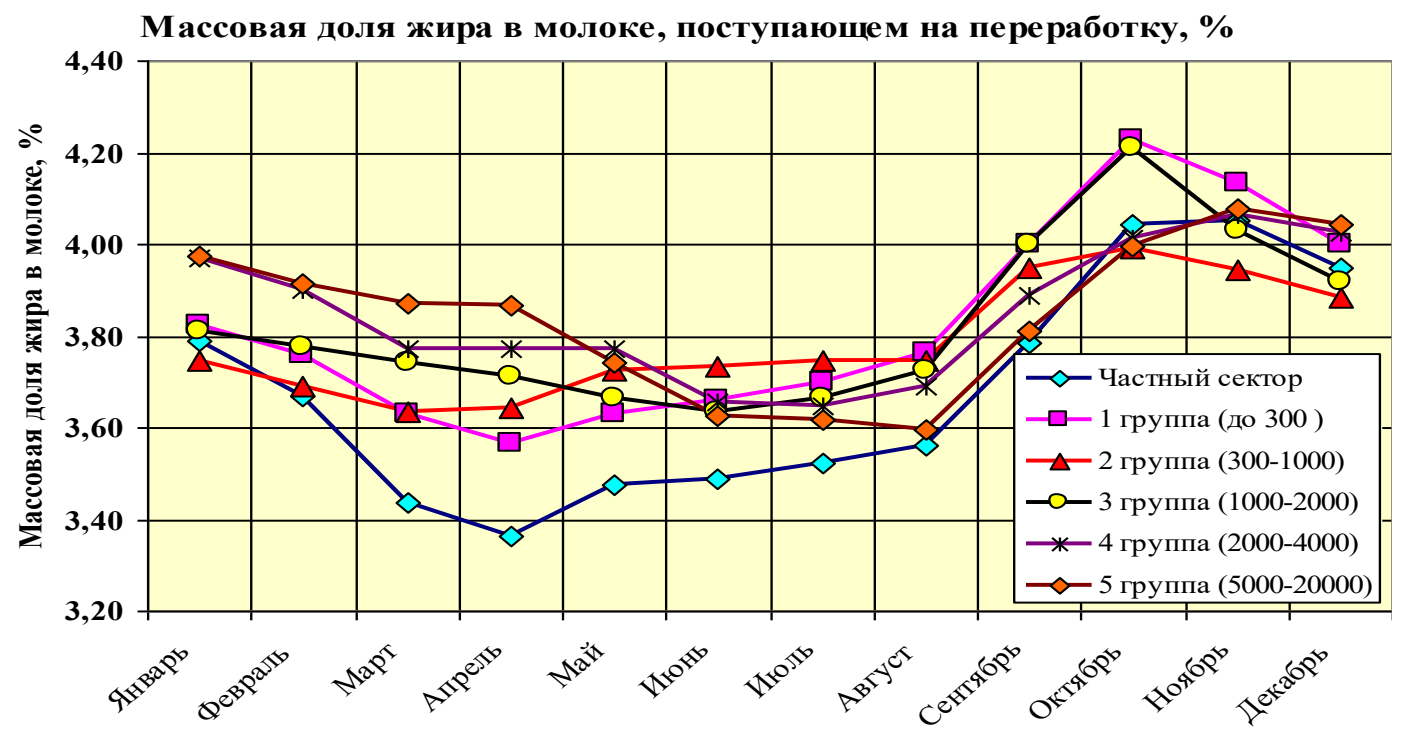

Puc. 4. Массовая доля жира в молоке от различных хозяйств 


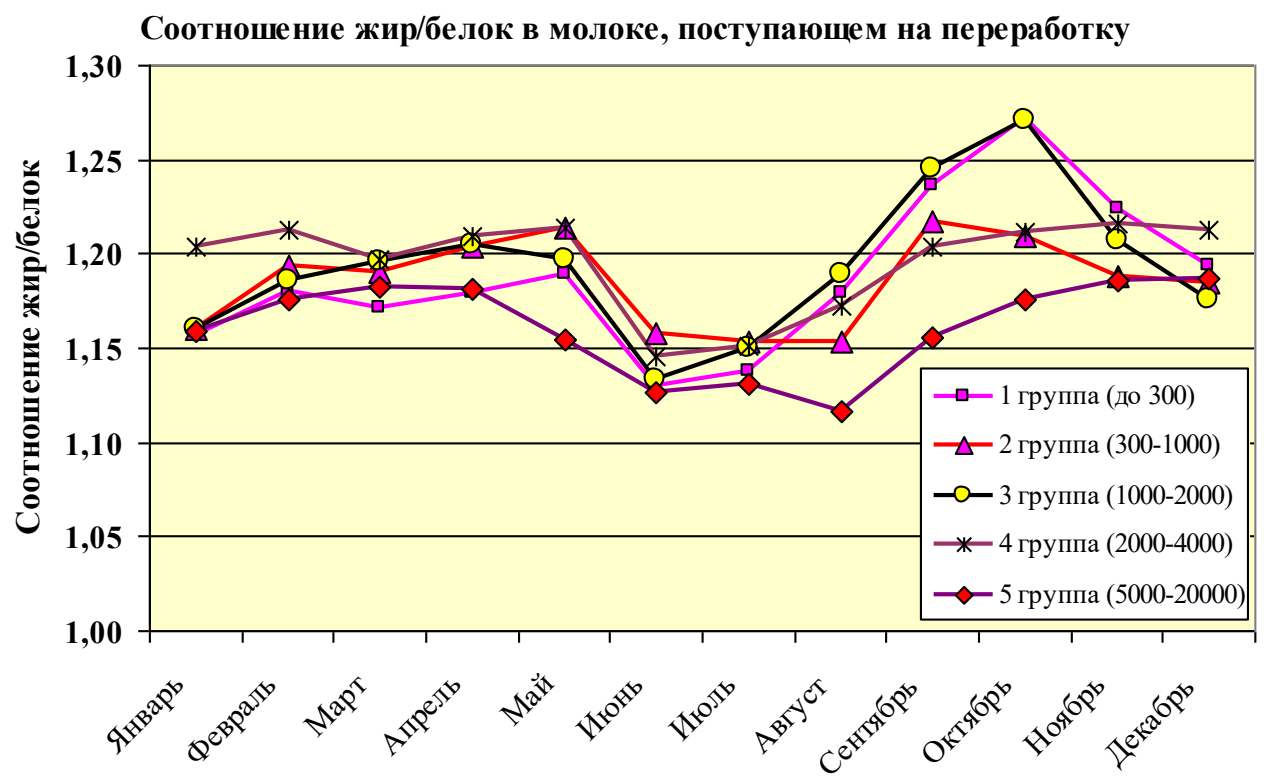

Puc. 5. Соотношение жир/белок в молоке в течение года

пы хозяйств, с суточными поставками молока более 5000кг.

Молоко, поступающее от частных хозяйств, по нашим данным, имело в среднем массовую долю жира 3,56\%, и массовую долю белка, - 3,0\%. Его доля в общих поставках молока не превышает 10\%. Для частного подворья характерно отсутствие породистого скота и возможностей правильного кормления, что объясняет несбалансированность состава молока (по соотношению жир-белок).

При выработке сыров значение имеет соотношение и количество жира и белка в исходном молоке. От этого зависит выход сыра, качество готового продукта. При низком содержании белка в молоке в конечном итоге сырный сгусток получается дряблым, зерно плохо обрабатывается, образуется много «сырной пыли», которая без применения специальных мер может быть безвозвратно утеряна.
Реальное соотношение жир/белок в поступающем молоке колеблется. Наибольшее количество молока поступает в период: июнь-август. В этот период соотношение составляло от 1,14 до 1,18 . Большая сезонность поставок молока на «Белебеевский МК» (она составляет 0,38) вынуждает принимать ряд мер, одной из которых является корректировка технологических режимов выработки сыра.

Сезонные изменения в составе и качестве молока должны быть учтены при производственном планировании и формировании ассортимента выпускаемой продукции. Но кардинальной задачей является организация более равномерного производства молока-сырья в течение года. Тем более, что примеры этому имеются (Ленинградская область, Московская область, Краснодарский край), где коэффициент сезонности выше среднего значения по России.

\section{Библиографический список}

1. http://www.dairyunion.ru/news-mol-market/

2. https://www.milknews.ru/index/novosti-moloko_12975

3. Молочная индустрия мира и Российской Федерации/Ежегодник, М. - 1915

4. https://www.milkprice.ru/news/8430-kratkii-obzor-rynka-moloka 